\title{
Online Katalog der Universitätsbibliothek der LMU München ISBN/ISSN/ISMN 9788366675599
}

Universitätsbibliothek der LMU München

80539 München, Germany

(C)2021 (September 16)
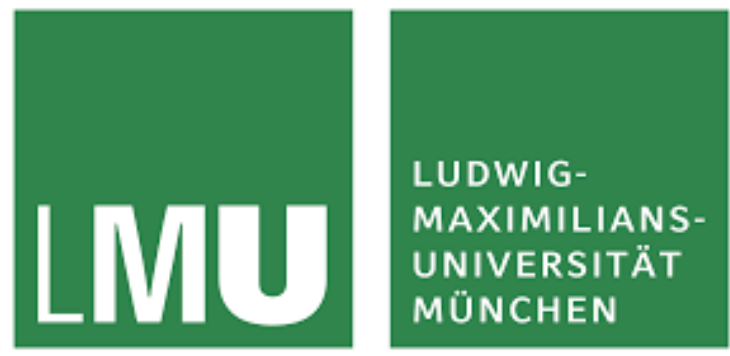

https://opac.ub.uni-

muenchen.de/TouchPoint/start.do?Query=1035\%3d\%22BV047416805\%22IN\%5b2\%5d\&View= sunrise \&Language $=$ de 


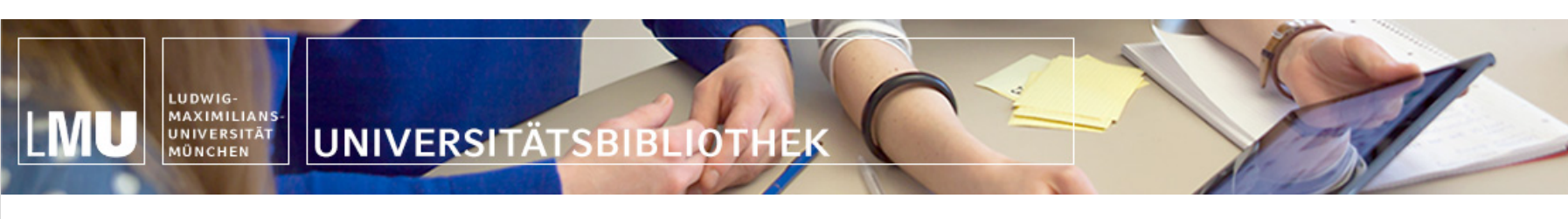

Sprache: deutsch

Suche $>$ Merkliste
Suche nach:
Zurück zur Trefferliste
믐 Drucken Versenden 四 Speichern $\$$ Suchdienst einrichten Permalink

Online Katalog der Universitätsbibliothek der LMU München (1/1)

Vor-Ort-Services an der UB

Ablegen in:

Temporäre Merkliste $\quad \checkmark \quad \mathrm{OK}$

\section{A Mindsponge-Based Investigation into the Psycho-Religious Mechanism Behind Suicide Attacks}

Autor: Vuong, Quan-Hoang

Ort, Verlag, Jahr: Warsaw ; Berlin, Sciendo, [2021]

Umfang: 1 online resource (127 pages)

ISBN/ISSN/ISMN 9788366675599

Seit dem 02.09.2021 gelten in

Hochschul- und

Bibliotheksgebäuden der 3G-

Grundsatz (geimpft, genesen, getestet) sowie Maskenpflicht. Dies gilt auch für die Abholung zuvor bestellter Medien und deren Rückgabe, für die Nutzung der Leseplätze und das Scannen und Kopieren. Weitere Informationen finden Sie auf unserer Webseite.

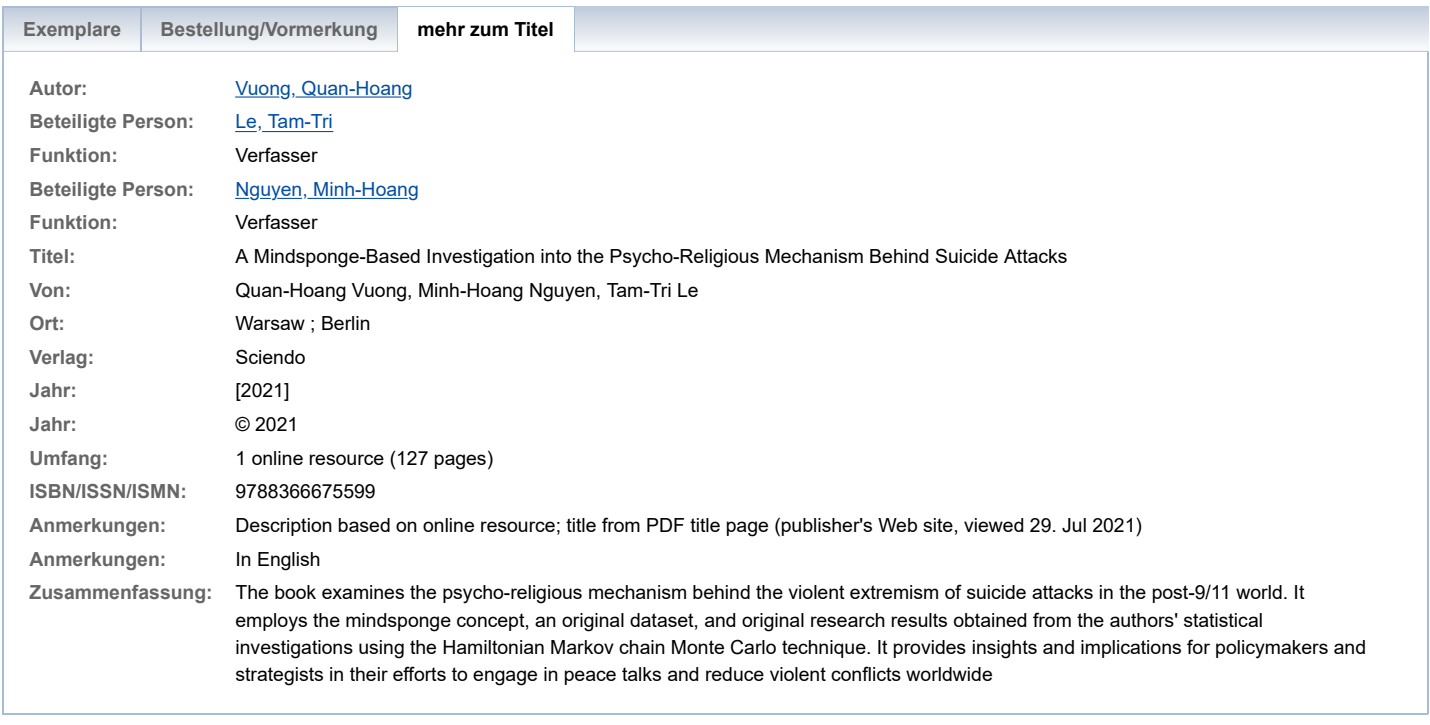

